\title{
On the Influence of Literary Works on Reading Motivation of British and American Literature
}

\author{
Bingfa Wu \\ Affiliated Secondary School of Arts, Sichuan Conservatory of Music, Sichuan 610000, China
}

Keywords: British and American literature, literary works, reading motivation, influence.

\begin{abstract}
British literature in the U.S. occupies an important proportion of the entire literary market in the West and plays a key role in the development of the world. The ideas and aesthetics embodied in the works are all elements that we need to appreciate and analyze. When we read English literary works, we can make a breakthrough in our own language level. At the same time, when reading, we can experience the differences of thoughts, feelings, and differences between foreign countries and enjoy reading. This article mainly analyzes the motive of English reading, and discusses the impact of literary works on our reading, hoping to get the approval of relevant personnel.
\end{abstract}

\section{Introduction}

In fact, the so-called literary works are a place for sustenance of emotions. In the articles, they can show local culture and human feelings, and spread some thoughts, feelings, thoughts, and cultures to people all over the world, so that people can feel the unique charm of British and American cultures. Specifically, in our research, the key is to understand the Anglo-American culture first. The main means is to constantly understand and understand the emotions in the works and to integrate them with the authors.

\section{The role of cultivating reading motivation}

As contemporary students can improve their English proficiency by reading English, only the motivation of students to read British and American cultures is cultivated. This is the act of forming British and American literary works [1]. Previously it was only a single form of reading. Now it will adopt a new style of English-American literature reading. This will enhance students' language learning ability and will also understand some of the cultural characteristics of the United Kingdom and the United States. It will be helpful for future English learning. Therefore, in order to achieve teaching goals, we need to use the English and American literature reading teaching model in learning English. Its motivation for reading is also very important. Only when students actively read the book will they be able to understand more deeply the relevant contents of the literary works. The content covered will only be able to learn English in constant thinking, strengthen its own appreciation ability, and enable students to gradually increase their interest in learning [2].

We are young people in the information age. There can be many sources of knowledge. However, the knowledge that is brought to us by reading is not comparable to the Internet. Only by reading deep within one's own heart can we truly comprehend all the thoughts and emotions expressed in literature. British and American literature reading can enable students to come into contact with a large amount of authentic English vocabulary, so that students can use more than one word, expand their knowledge and creativity, and provide students with a sense of aesthetics. In particular, English itself is an art language, and this total charm continues to show in reading. Readers can choose their own literary works to read, so that they will get the nutrition and knowledge they want in reading, and at the same time, they will also improve the reader's thoughts and emotions. At the same time, some literary works have their own attractiveness. Their unique charm attracts a large number of readers to do reading research. For some simple English learning enthusiasts, they prefer to read literary works and understand different cultural environments. All thoughts and connotations of the works are 
constantly improving their sentiments and are very important for cross-cultural communication between Chinese and Western cultures.

\section{A brief analysis of the meaning of reading motivation of British and American cultures}

The so-called reading motivation is a mechanism that has a certain effect on reading. In fact, reading English and American literature with a certain purpose, for current students, there will be a strong motivation when reading, in fact, in order to get more information and deal with examinations, the motivation at this time will be considered as a tool, to achieve a certain purpose of the means, with a purpose of reading, but will be more careful and meticulous, such as in order to strengthen their listening ability, students will often read English and American literature, to strengthen their own listening and speaking skills, and lay a solid foundation for future examinations, the other is that when we read English and American, we chose to read literary works in order to satisfy our interest and curiosity. In fact, the main purpose is to make students get a certain interest in reading, interest is the source of all learning, only if they are interested in doing one thing, will it be outstanding, and English reading is no exception. On the basis of interest, reading can be made more thorough and the quality of English learning can be improved. If the students are truly satisfied and interested in reading, they will be more active and consciously devoted to practical reading or learning, and will always stick to the habit of reading, and reading skills will be greatly improved after a long time. In order to improve, the connotations and emotions manifested in literary works have been correspondingly enjoyed. Therefore, for current teachers, only by improving the students' interest in reading British and American literature can they be better taught in English, and at the same time, communication between Chinese and foreign countries will be simplified.

The language in excellent literary works is vivid, image and they all have profound connotations. Students are required to read and analyze over and over again. The contents covered in the literary works can help students learn knowledge and improve their overall quality. The language used in literary works is derived from our daily life. There are some aspects that are indeed higher than ours. The content is easy to understand and is particularly suitable for students' learning. English used in British and American literary works is also an essential sentence in our daily life. It is very useful for students' learning and use. It can improve students' thinking ability and reading ability, and can also improve students' aesthetic feelings [3]. For example, "Jane Eyre" is a well-known literary work in the West. The author expresses the character and thoughts and feelings of the hero in the whole article. The works use ample language to show the protagonist's longing for love and his own positive and optimistic attitude. The protagonist Jane insists on pursuing his own love, but he never loses his self-esteem. Such literature is very helpful to readers for learning. Through reading, you can feel the author's strong feelings and thoughts. At the same time, you can learn a lot of English vocabulary and grammar in reading so that you can better understand the cultural history of the United Kingdom and the United States. We are now learning English better.

\section{The importance of literary works for improving the reading of English literature}

(1) Improve readers' language skills

If the reader has a strong language ability, then it will be much simpler when it comes to literary reading, and it will be less strenuous to understand. Therefore, in the case of the training of reading motivation of British and American literature, we must first improve the language ability of readers. Before reading, we must develop our language and understanding skills through long-term language environment and language contact. Language sense can promote English learning. British and American literary works can focus on cultivating the linguistic competence of readers, and the quality of reading can be more effectively improved through the learned linguistic knowledge. In previous English reading, the teacher mainly required students to master grammar, and often did not attach importance to the connotation and historical and cultural background of the work. It was unreliable for students to remember, and doing so would make students bored with this single teaching method. 
Feel the classroom is boring. Therefore, in order to stimulate the students' reading motivation, teachers must first understand the literary works, fully understand the cultural connotations and ideas, and understand the specific character events in the literary works. Only when the teachers understand them first can students be encouraged. To read, so as to gradually improve the students' reading motivation, the problems encountered by students in the process of reading, teachers can give answers, and even everyone sat together to discuss reading content, the purpose is to enable students to actively study their knowledge and read the literary works on their own, which is very beneficial to the future physical and mental development. If such a teaching method is adopted, students can enhance their own observation and innovation through long-term reading, and in the process of reading, they can promote the cultivation of emotions and strive to be a comprehensive talent with both ideas and professional skills [4].

(2) Promoting cross-cultural communication between China and the West

Now is the age of education. Most of our knowledge is generated through reading. Through reading, we can more accurately understand the world and integrate it into social life. If we read British and American literary works, we can learn western cultural background and thoughts and emotions in the works we read. In fact, reading British and American literary works also requires certain knowledge and skills. Only the English knowledge is strong and the feelings are rich will result in a better reading. This will play a key role in the future cross-cultural communication between China and the West. If readers have a single reading of knowledge, they cannot understand the historical background and social life of the works. It is difficult to understand the thoughts and feelings in the works. There is no way to really understand the author's writing intentions and there is no way to grasp the core content of the works. Therefore, if we want to better read British and American literary works, we should first understand the cultural forms and social backgrounds of the Anglo-American region, so that we can better understand the background in reading, and we can also improve the motivation of reading. Through the understanding of British and American cultures, we gradually discovered that the difference between literary works is mainly the difference between religions. Under different religious differences, works also have different social backgrounds [5]. For example, the well-known literary work "The Old Man and the Sea" mainly describes the process of an old man fighting with sharks. It embodies the indomitable character of man in literature and also realizes the value of the individual. It mainly embodies Western values, which are different from our traditional Chinese culture. By reading "The Old Man and the Sea", we can have a more vivid understanding of western knowledge and values, and always feel the cultural differences and aesthetics between different cultures. If we will experience such cultural differences in future readings, and will continue to increase the exchanges between more cultures, this time will increase our awareness of cross-cultural learning, such a long time will increase our awareness of cross-cultural learning and will be very beneficial to our learning and language formation in the future. Another example is another literary work "The Gadfly". The main description of the article is the revolutionary career of the host bull. This article affirms the hero's attitude towards life and at the same time is an approval of the revolutionary cause. This is a revolutionary tragic literary work. It is representative of the appreciation of Chinese and Western academic writings. Readers will have a certain degree of cognition of British and American cultures through their reading of "The Gadfly". At the same time, they will also understand the difference between British and American revolutionary undertakings and the Chinese revolution. Through a simple literary work, they will make themselves more aware of foreign cultural and social backgrounds. The formation of cultural awareness is very helpful.

(3) To make readers' ideas sublimate

In some of the famous literary works in Britain and the United States, more practical and popular English vocabularies are used. This will be more effective for students' future learning and can make English even more advanced. Therefore, in our specific practical teaching, teachers should select some excellent literary works for students to read, through repeated reading to understand the background of the times appearing in the text, and understand what the work is in such a situation to write such an article, after reading, everyone appreciates through the English language. Everyone 
discusses the key points and thoughts in the text. As time passes, they will improve students' ideological consciousness and they will also be sublimated to adapt. Therefore, it is very beneficial to learn appropriate reading motivation for students to improve their English skills and emotions. In many excellent literary works, the character of the protagonist is quite distinct. He represents a symbol of culture. At the same time, it also reflected the social background at that time. From the frustrations and difficulties encountered by the characters, they would associate with the social environment at that time, the way of life between people, the actual experience of the author, the content to be expressed by the author, and the emotional achievement of the author. Resonance reflects the social and cultural background of Britain at the time through simple literary works [6].

\section{Conclusion}

In summary, in the reading of British and American literary works, we must focus on motivating reading. Motivation training is used to achieve a goal. In fact, it is the cultivation of reading interest. Only the readers are really interested and can read it later. Participate in the self-involvement. Therefore, in order to better understand British and American literature, we should master the motivation to read certain readings. In fact, the literature we read more often is not just text and beauty. The contents and ideas that we cover are also something we should understand. Only by studying the purpose and thoughts and feelings of literary writers can we read this article more clearly. According to the historical background of the written literature, we can understand the background of the British and American family, stimulate the interest of reading, and at the same time make the cross-cultural awareness between Chinese and Western cultures for the future work and study to lay a solid foundation.

\section{Acknowledgements}

About the author: Wu Bingfa, male, Chengdu, born 1974.4 months. Master of Foreign Studies, Sichuan University, Research Direction, British \& American Literature, Lecturer, Serving School, Secondary School of Arts, Sichuan Conservatory of Music.

\section{References}

[1] Deng Yun. On the influence of literary works on the reading motivation of British and American literature [J]. Offers, 2017, (39): 209.

[2] Song Liying. The influence of literary works on reading motivation of British and American literature [J]. Language Construction, 2013, (24): 47-48.

[3] YIN Shu-ying. A Preliminary Exploration of British and American Literary Works [J]. New Era of Education E-zine (Teacher's Edition), 2018, (3): 86.

[4] Liu Chunjie. An Approach to Improve Reading Comprehension Ability in British and American Literary Works [J]. Modern Vocational Education, 2017(14): 47.

[5] Wang Zhixiong, Li Xiaoyan. An Analysis of Reading and Appreciating Strategies in British and American Literary Works [J]. Seeking Guidance, 2015(21): 115.

[6] ZHANG Jing, CUI Ying. Cultural Differences and Reading Teaching in English and American Literature [J]. Language Construction, 2015(20): 18-19. 